\title{
Impact of prescription isodose level and collimator selection on dose homogeneity and plan quality in robotic radiosurgery
}

\author{
Alexandra Hellerbach ${ }^{1}$ (D) - Markus Eichner ${ }^{1}$ Daniel Rueß ${ }^{1} \cdot$ Klaus Luyken $^{1} \cdot$ Mauritius Hoevels ${ }^{1}$. \\ Michael Judge ${ }^{2} \cdot$ Christian Baues $^{2} \cdot$ Maximilian Ruge $^{1} \cdot$ Martin Kocher $^{1} \cdot$ Harald Treuer $^{1}$
}

Received: 8 April 2021 / Accepted: 17 October 2021 / Published online: 9 December 2021

(c) The Author(s) 2021

\begin{abstract}
Purpose In stereotactic radiosurgery (SRS), prescription isodoses and resulting dose homogeneities vary widely across different platforms and clinical entities. Our goal was to investigate the physical limitations of generating dose distributions with an intended level of homogeneity in robotic SRS.

Methods Treatment plans for non-isocentric irradiation of 4 spherical phantom targets (volume $0.27-7.70 \mathrm{ml}$ ) and 4 clinical targets (volume $0.50-5.70 \mathrm{ml}$ ) were calculated using Sequential (phantom) or VOLO ${ }^{\mathrm{TM}}$ (clinical) optimizers (Accuray, Sunnyvale, CA, USA). Dose conformity, volume of $12 \mathrm{~Gy}$ isodose (V12Gy) as a measure for dose gradient, and treatment time were recorded for different prescribed isodose levels (PILs) and collimator settings. In addition, isocentric irradiation of phantom targets was examined, with dose homogeneity modified by using different collimator sizes.

Results Dose conformity was generally high $(\mathrm{nCI} \leq 1.25)$ and varied little with PIL. For all targets and collimator sets, V12Gy was highest for PIL $\geq 80 \%$ and lowest for PIL $\leq 65 \%$. The impact of PIL on V12Gy was highest for isocentric irradiation and lowest for clinical targets ( $\mathrm{VOLO}^{\mathrm{TM}}$ optimization). The variability of V12Gy as a function of collimator selection was significantly higher than that of PIL. V12Gy and treatment time were negatively correlated. Plans utilizing a single collimator with a diameter in the range of $70-80 \%$ of the target diameter were fastest, but showed the strongest dependence on PIL.

Conclusion Inhomogeneous dose distributions with PIL $\leq 70 \%$ can be used to minimize dose to normal tissue. PIL $\geq 90 \%$ is associated with a marked and significant increase in off-target dose exposure. Careful selection of collimators during planning is even more important.
\end{abstract}

Keywords Cyberknife $\cdot$ Dose gradient $\cdot$ Homogeneity index $\cdot$ Collimator influence $\cdot$ Treatment time

The authors Alexandra Hellerbach and Markus Eichner contributed equally to the manuscript.

Availability of data and material The dataset of the spherical phantom targets can be requested from the corresponding author. The clinical raw data is provided by the Department of Stereotaxy and Functional Neurosurgery, Centre of Neurosurgery, University Hospital of Cologne.

Code availability Not applicable

Alexandra Hellerbach

alexandra.hellerbach@uk-koeln.de

1 Faculty of Medicine and University Hospital Cologne, Department of Stereotaxy and Functional Neurosurgery, University of Cologne, Kerpener Straße 62, 50937 Cologne, Germany

2 Faculty of Medicine and University Hospital Cologne, Institute of Radiation Oncology, University of Cologne, Cologne, Germany 


\section{Introduction}

Stereotactic radiosurgery (SRS) is a well-recognized and successful treatment modality for patients with malignant or benign intracranial pathologies [1-6]. Its use and importance are increasing as modern imaging techniques allow early detection of small brain lesions [7] and as recent advances in systemic therapy often lead to the need for further radiotherapy of, for example, new brain metastases and meningeomas, which is generally possible with SRS [8].

SRS differs in several aspects from standard radiation therapy, especially with regard to fractionation, target size, safety margins and dose prescription [9-12]. In SRS, very high doses are applied to the target volume in one or only a few fractions, which imposes strict requirements on minimizing the dose to normal brain tissue. This is achieved by minimizing the safety margins using stereotactic head fixation or inter- and intrafractional imaging, by conforming the high doses to the shape of the target and by a steep dose fall-off at the periphery of the target volume. To prevent the dose from spreading to normal tissue, high demands are placed on the accuracy of the beam guidance and the collimation of the radiation field. In many SRS systems, a set of cones with fixed circular field sizes are used for this purpose. With these circular collimators, dose conformation to the target volume can either be achieved by superposition of multiple isocentric shots ('sphere packing') or by application of a non-isocentric beam array adapted to the target shape [13]. The use of sphere packing inevitably leads to rather inhomogeneous dose distributions with cold and hot spots, whereas non-isocentric irradiation, e.g., with a robotguided LINAC, has the potential to achieve more homogeneous dose distribution within the target. Therefore, different techniques for SRS such as Gamma Knife, Cyberknife and LINAC usually use different isodose prescription regimens [14]. Whether a homogeneous or an inhomogeneous dose distribution within the target is desired is controversial and depends on the clinical situation. For targets such as brain metastases, dose escalation within the target appears advantageous since these do not contain healthy tissue. In contrast, a more homogeneous dose distribution appears suitable for targets such as vestibular schwannoma or pituitary adenoma, as healthy tissue may also be included in the target volume [12, 15-18].

The aim of this theoretical study was to investigate the physical constraints for the intended generation of homogeneous or inhomogeneous dose distributions in robotic radiosurgery. In particular, the influence of the prescription isodose level (PIL) and collimator selection on dose conformity, volume of $12 \mathrm{~Gy}$ isodose (V12Gy) as a measure for dose gradient and treatment time were investigated.

The influence of the PIL on dose gradient to surrounding tissue has already been analyzed for different SRS platforms
[19-23], although there was only one publication related to robotic stereotactic radiosurgery [22]. Contrary to that study we focused our analysis on the physical principles by eliminating the influence of planning skills and by including the influence of collimator sizes. In our study, we perform a systematic analysis including an ideal isotropic model, isotropic as well as non-isotropic phantom plans, and clinical cases to evaluate the impact of dose homogeneity and the effects of different collimator choices on SRS plan quality using a large amount of single-target SRS plans.

\section{Materials and methods}

\section{Ethics statement}

This retrospective study was approved by the local ethics committee of the University Hospital of Cologne (file number 16-476).

\section{Isocentric phantom irradiation}

Dose-volume histograms (DVHs) for an artificial spherical target with a diameter of $8 \mathrm{~mm}(0.27 \mathrm{ml})$ and a shell with an outer diameter of $28 \mathrm{~mm}$ were calculated assuming an isotropic model. Within this model, the focal dose distribution $D$ delivered by a conical collimator is given by

$D(R)=2 \pi \int_{0}^{\pi / 2} d \theta \sin \theta O C R(R \sin \theta)$

where $O C R$ is the measured beam profile of the collimator and $R$ is the radial distance from the isocenter [24, 25]. The dose homogeneity, often described by a homogeneity index HI (HI = 100/PIL), was modified by using different collimator sizes. Collimators with diameters of 5.0, 7.5, 10.0 , and $12.5 \mathrm{~mm}$ were used and a peripheral dose of $20 \mathrm{~Gy}$ was applied.

To verify the assumptions made in the isotropic model, dose distributions of isocentric beam sets were calculated using the Cyberknife planning software Precision 2.0.1.1 (Accuray, Sunnyvale, CA, USA) for a spherical phantom target with a diameter of $8 \mathrm{~mm}(0.27 \mathrm{ml})$. Due to the limited number of beam directions (the isocentric optimization algorithm for the full path head used allows a maximum of 133 beam directions), a slightly non-isotropic dose distribution emerged. The same collimators as in the isotropic model were used for the optimization, and equally weighted beams (non-conformal beam weights) and conformal beam weights (weighting of the beams to adapt the irradiation field to counteract non-isotropy) were applied. Around the phantom's target a shell with an outer diameter of $28 \mathrm{~mm}$ 
(corresponds to $10 \mathrm{~mm}$ distance to the target surface) was generated to analyze the influence of PIL and collimator diameter on dose gradient using dose-volume histograms of the target and the shell. As in the isotropic model, a peripheral dose of $20 \mathrm{~Gy}$ was applied.

\section{Non-isocentric phantom irradiation}

Using the non-isocentric irradiation technique of the Cyberknife, the influence of PIL and collimator selection on plan quality was evaluated. For this purpose, 4 spherical targets with volumes of $0.27,0.55,2.16$ and $7.77 \mathrm{ml}$ were generated in the center of a virtual spherical CT phantom. The Sequential optimization algorithm of the Cyberknife [26] was used to calculate treatment plans for different sets of collimators (including the Iris collimator [27]) and for different PILs (40-90\% in steps of 10\%). The same Sequential optimization scripts was used for all plans, consisting of (i) optimizing coverage of the target volume with the prescribed dose, (ii) optimizing conformity by sequentially minimizing the dose in 4 shell structures, and (iii) minimizing the total monitor units (MU) of the plan. Shells with distances of $3,7,12$, and $20 \mathrm{~mm}$ to the target surface were used for optimization, with each shell having a thickness of $1 \mathrm{~mm}$. Identical optimization objectives and weights were used except for the maximum dose, which was manually adjusted accordingly in each case to vary the PIL. For better comparability and in order to keep the influence of the coverage on the plan results to a minimum, uniform coverage were aimed for all plans. Using the Sequential optimization, full coverage of the targets could be achieved for all spherical phantoms by normalizing the minimum target dose to $20 \mathrm{~Gy}$.

\section{Non-isocentric irradiation in clinical cases}

Furthermore, 4 clinical targets with volumes of $0.50,0.92$, 2.01, and $5.68 \mathrm{ml}$ (supplementary material, Figure S 1) were selected from our patient archive. A sample was chosen that was representative of the spectrum of brain metastases treated with Cyberknife and comparable in size to the phantom targets. The Cyberknife's VOLO ${ }^{\mathrm{TM}}$ optimizer [28] was used to calculate treatment plans for different sets of collimators including the Iris collimator as well as for different PILs $(50-90 \%$ in steps of $10 \%$ and $\geq 90 \%)$. The smallest field size of the Iris collimator was $7.5 \mathrm{~mm}$ according to the manufacturer's restriction for clinical applications. Similar parameter settings and optimization aims and weights were used as for the applied clinical plans, except for the maximum dose, which was adjusted accordingly to vary the PIL. In detail, 9 shells with distances of 2, 5, 10, 15, 20, $30,50,70$, and $100 \mathrm{~mm}$ to the target surface were used for optimization, the total MU penalty value ranged between
0.5 and 0.7 and the maximum MU per beam was set to 150 for three clinical targets and 120 for one target. In all plans, the marginal dose was adjusted to $20 \mathrm{~Gy}$ and to an intended coverage of $99.5-99.8 \%$ as applied in the clinical plan. For example, with a prescription of $20 \mathrm{~Gy}$ at $65 \%$ PIL, the planner aims to achieve a maximum dose of $30.77 \mathrm{~Gy}$, while a volume of $99.5 \%$ should receive $20 \mathrm{~Gy}$.

\section{Analysis of plan quality}

The influence of PIL and collimator selection on plan quality was analyzed using the conformity index nCI (reciprocal of the conformation number [29]), V12Gy, and the treatment time. Other metrics for the dose gradient were the volume of the 4,8 , and $10 \mathrm{~Gy}$ isodose outside the target (V4Gy, V8Gy, V10Gy), the gradient index GI [30], and the gradient measure GM [31]. The used quality indices were defined as followed:

$n \mathrm{CI}=\frac{\mathrm{PTV} \cdot \mathrm{PIV}}{\left(\mathrm{PTV}_{\mathrm{PIV}}\right)^{2}}$

$\mathrm{GI}=\frac{\mathrm{PIV}_{50 \%}}{\mathrm{PIV}}$

$\mathrm{GM}=\left(\frac{3}{4 \pi}\right)^{1 / 3} \cdot\left[\mathrm{PIV}_{50 \%}{ }^{1 / 3}-\mathrm{PIV}^{1 / 3}\right]$

where PTV is the planning target volume, PIV the prescription isodose volume, $\mathrm{PTV}_{\mathrm{PIV}}$ the planning target volume that is covered by the prescription isodose volume, and $\mathrm{PIV}_{50 \%}$ the volume that is encompassed by half of the prescription isodose. In addition to treatment time, the total number of monitor units (TotalMU) and the number of beams (nBeams) were recorded.

Two different optimizers are used in this study to examine whether the results are independent of the selected optimizer.

\section{Statistics}

The statistical analysis was performed using scatter plots and box plots. The Wilcoxon rank-sum test was used to assess the differences between V12Gy after grouping into 4 or 5 classes of the prescribed isodose level. The statistical dependence of V12Gy with the other gradient measures (V4Gy, V8Gy, V12Gy, GI, GM) and of the treatment time with TotalMU and nBeams was evaluated using Spearman's rank correlation coefficient $\rho$ where $p \leq 0.05$ was used as the significance level. Furthermore, we assumed a linear model with interaction terms for the relationship between 
a

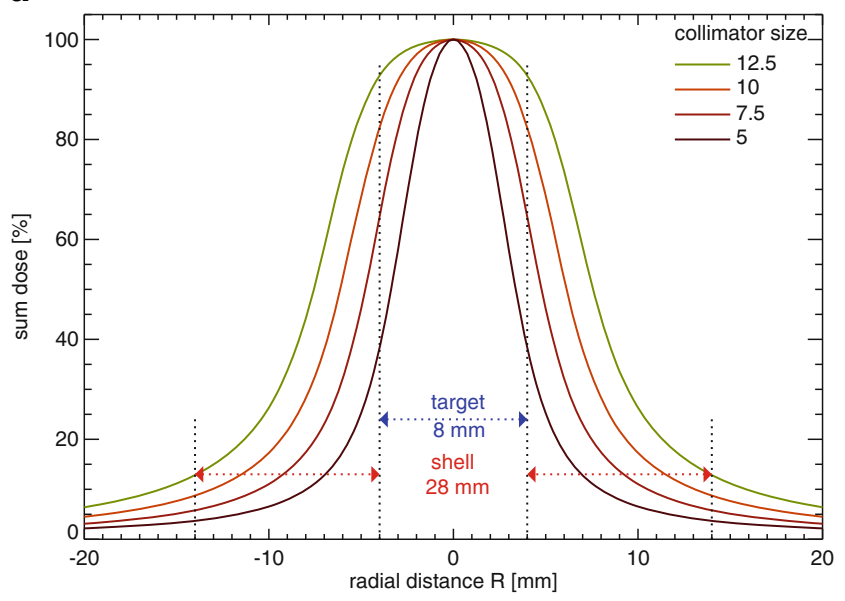

C

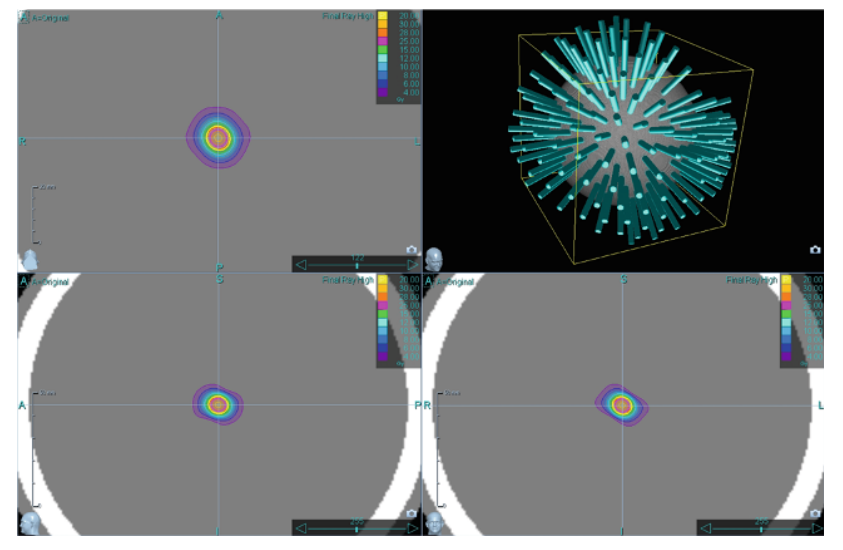

b

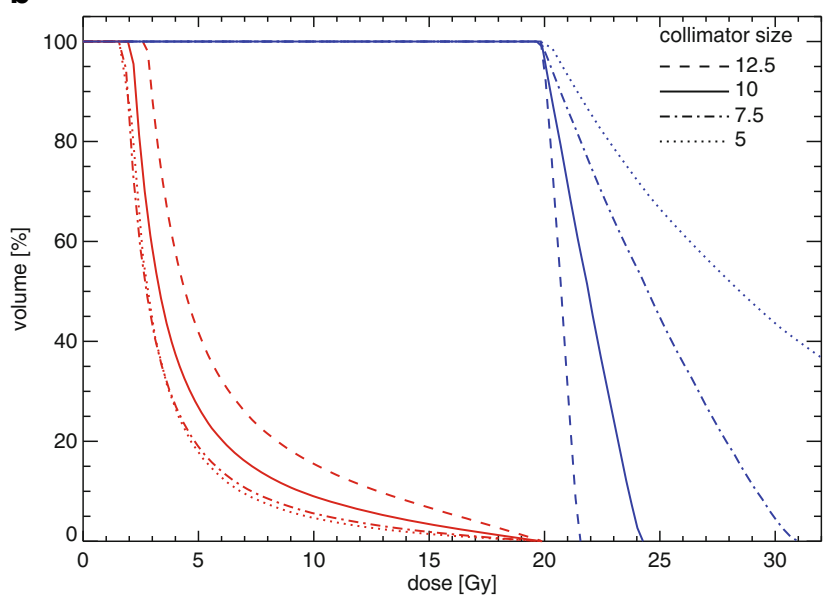

d

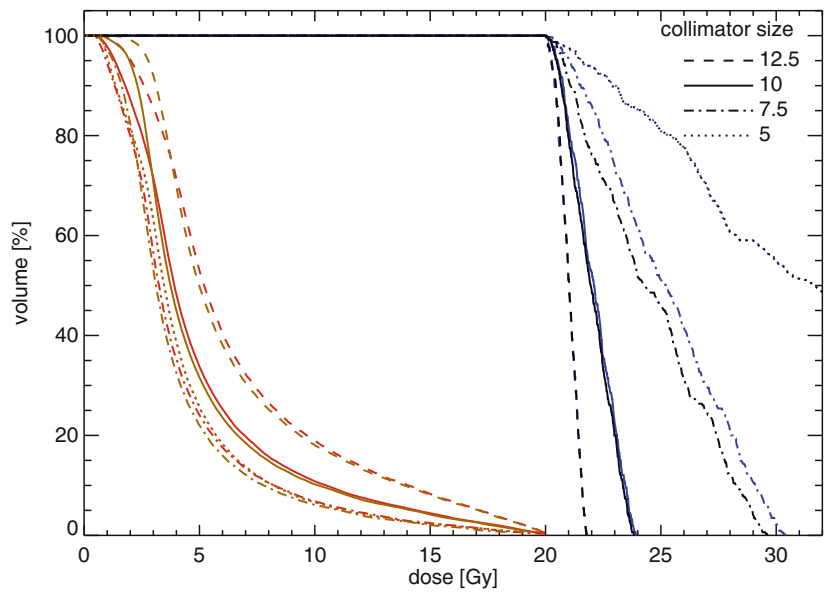

Fig. 1 a Theoretical dose distributions and $\mathbf{b}$ resulting dose-volume histograms for a spherical phantom target with a diameter of $8 \mathrm{~mm}(0.27 \mathrm{ml}$, blue) and a shell with an outer diameter of $28 \mathrm{~mm}$ ( red $)$. c Dose planning for an isocentric beam set with conformal beam weights at the Cyberknife and $\mathbf{d}$ resulting dose-volume histograms for two beam weight options for a $0.27 \mathrm{ml}$ spherical phantom target (conformal beam weights: black, nonconformal beam weights: blue) and a shell with an outer diameter of $28 \mathrm{~mm}$ (conformal beam weights: brown, non-conformal beam weights: red)

the dependent variable V12Gy and PTV, PIL and treatment time (TT):

$$
\begin{aligned}
\mathrm{V} 12 \mathrm{~Gy}= & \beta_{0}+\beta_{1} \cdot \mathrm{PTV}+\beta_{2} \cdot \mathrm{PTV} \cdot(\mathrm{PIL}-50 \%) \\
& +\beta_{3} \cdot \mathrm{PTV} \cdot(\mathrm{TT}-30 \mathrm{~min})
\end{aligned}
$$

The results were expressed as ranges or mean \pm standard deviation. Statistical evaluation was performed with R v3.6.3 (https://www.r-project.org).

\section{Results and discussion}

\section{Isocentric phantom irradiation}

Based on measured beam profiles and equation (1), the isotropic model was used to calculate the theoretically achievable dose distributions that would result from isotropic, isocentric irradiation of a spherical target. Fig. 1a shows the resulting dose distributions of the 4 smallest collimators of the Cyberknife. Using these collimators for irradiating a spherical target with a diameter of $8 \mathrm{~mm}$ with a peripheral dose of $20 \mathrm{~Gy}$ resulted in maximum doses of 52.1, 31.0, 24.3, and 21.6Gy for the collimator sizes 5.0, 7.5, 10.0, and $12.5 \mathrm{~mm}$ (Fig. 1b). The corresponding dose-volume histograms (DVHs) for dose prescriptions of $20 \mathrm{~Gy}$ at the $38 \%, 65 \%, 82 \%$, and $93 \%$ isodose levels clearly show the dose-sparing effect outside the target volume with simultaneous dose escalation within the target for the lower PILs associated with the smaller collimator sizes (Fig. 1b). The isotropic model was compared with dose distributions of isocentric beam sets calculated at the Cyberknife using the same target size and collimators (Fig. 1c). Application of non-conformal and conformal beam weights resulted in very similar DVHs (Fig. 1d). As in the isotropic model, the dose-saving effect in the 
a

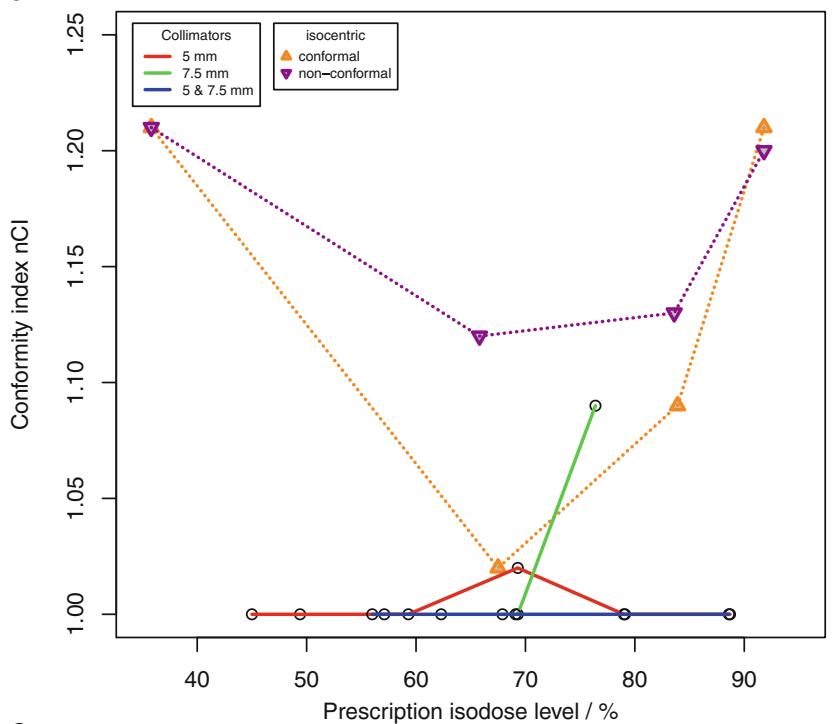

C

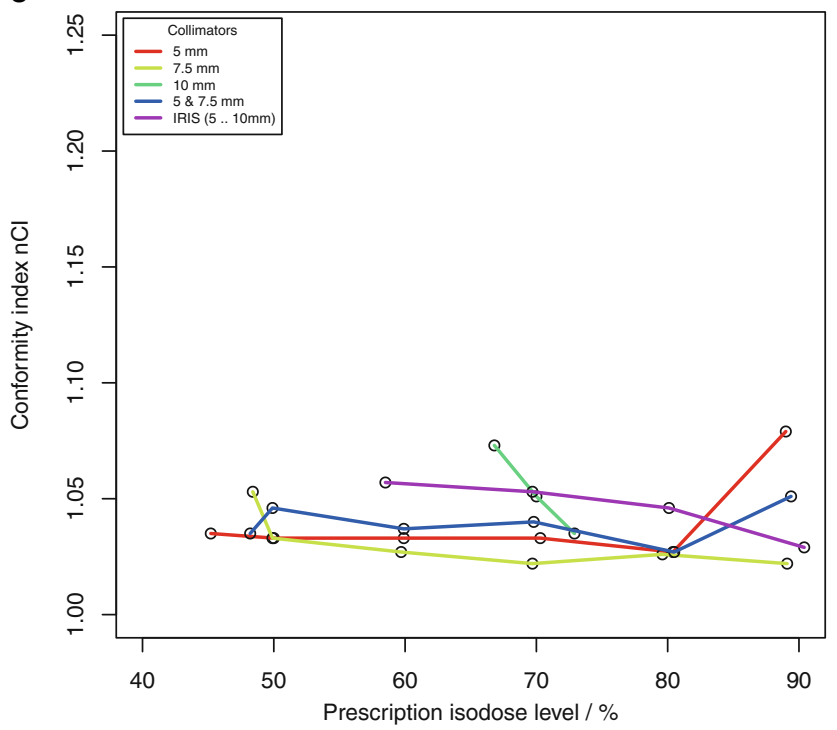

b

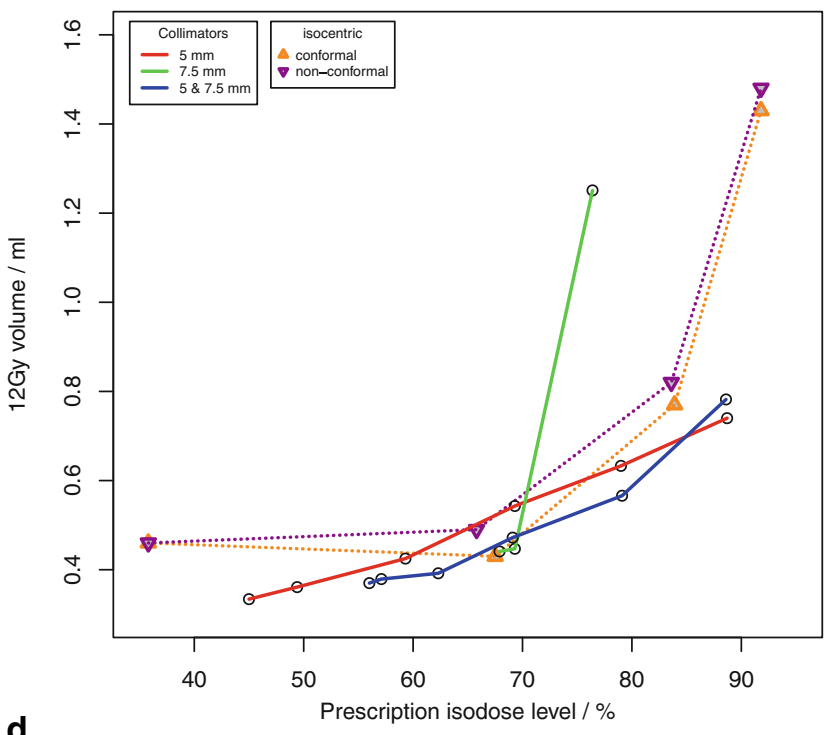

d

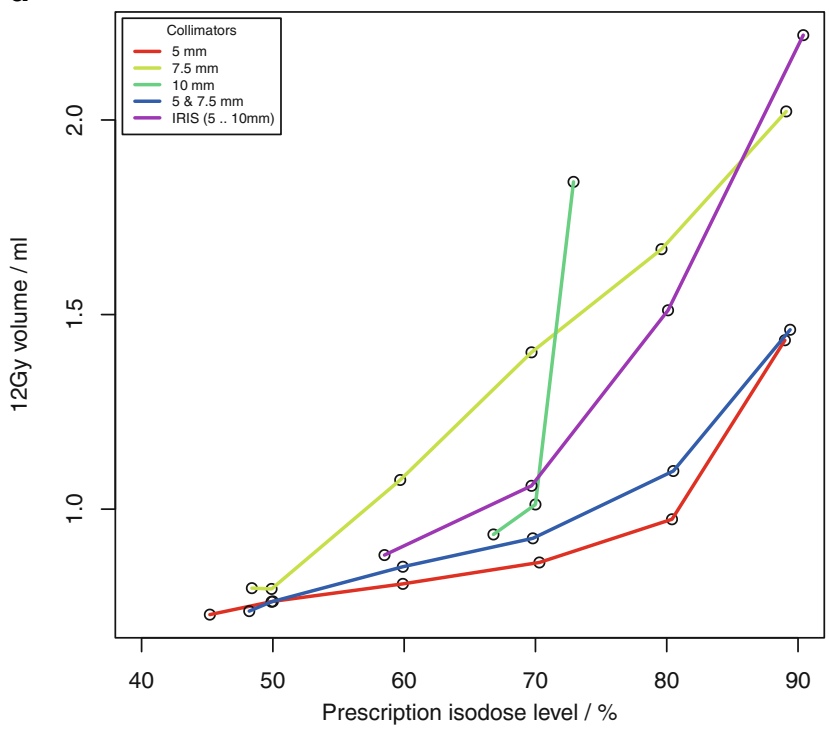

Fig. 2.1 a, c Conformity index nCI and $\mathbf{b}, \mathbf{d}$ volume of the $12 \mathrm{~Gy}$ isodose for 4 spherical phantom targets with volume $\mathbf{a}, \mathbf{b} 0.27 \mathrm{ml}, \mathbf{c}, \mathbf{d} 0.55 \mathrm{ml}$ as a function of the achieved prescription isodose level. a, b Results of the isocentric planning are also shown

surrounding shell and the dose escalation within the target volume was again clearly visible at the lower PIL. For example, dose planning for an isocentric beam set with conformal beam weights resulted in maximum doses of 55.9, 29.6, 23.8, and $21.8 \mathrm{~Gy}$ for the collimator sizes 5.0, $7.5,10.0$, and $12.5 \mathrm{~mm}$, while V12Gy was 1.7 and 3.1 times higher at isodose levels of $83 \%$ and $93 \%$, respectively, than at levels $\leq 65 \%$. Further results of the two beam weight options can be found in the supplementary material (Table S 1).

The results confirm that with isocentric irradiation, the dose-sparing effect at low PIL is mainly due to the size and shape of the beam profiles.

\section{Non-isocentric irradiation in phantom and clinical targets}

The ability to generate dose distributions with high conformity and steep dose gradient with an intended homogeneity using non-isocentric irradiation was investigated for 4 spherical phantom targets and for 4 clinical targets (supplementary material, Figure $S$ 1). For the phantom targets, a total of 110 treatment plans for 22 different collimator sets were computed using Sequential optimization (supplementary material Table $\mathrm{S} 2$ ). For the clinical targets, a total of 210 treatment plans for 30 different collimator sets were calculated using $\mathrm{VOLO}^{\mathrm{TM}}$ optimization (supplementary material, Table S 3). Fig. 2 (Fig. $2.1+$ Fig. 2.2, phantom targets) and Fig. 3 (Fig. $3.1+$ Fig. 3.2, clinical targets) show 


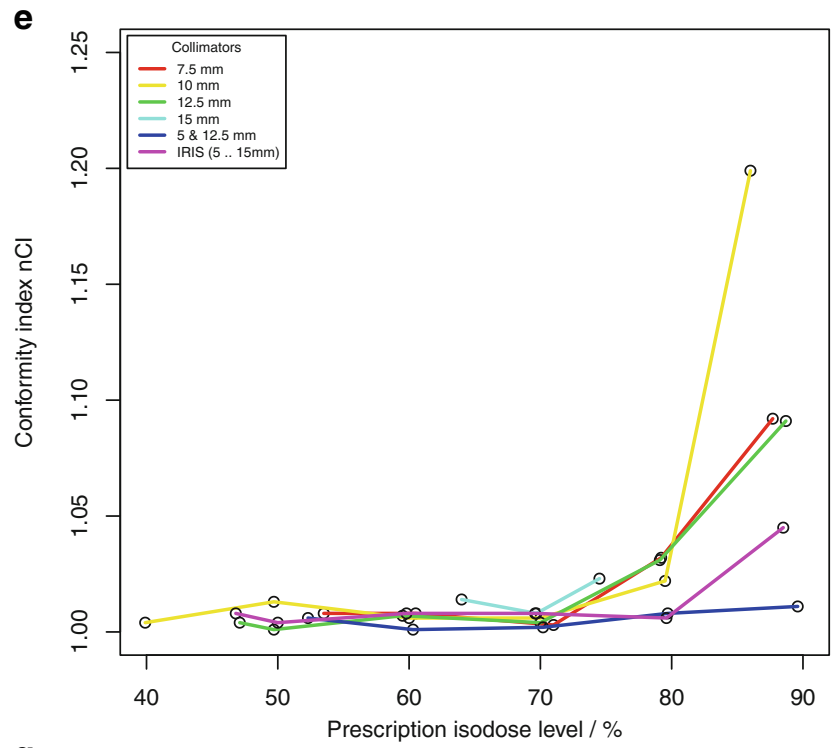

g

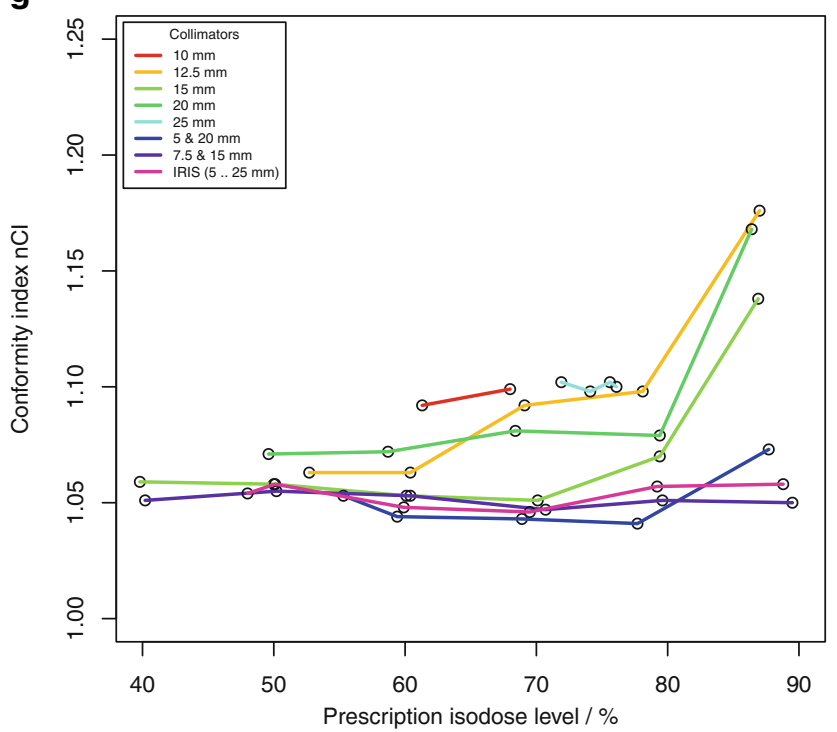

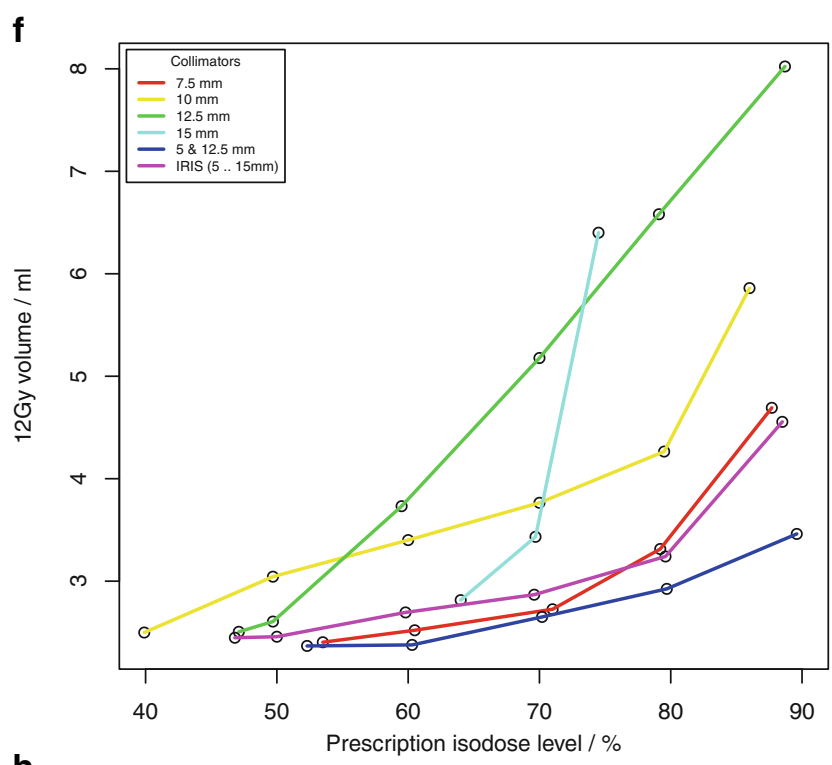

h

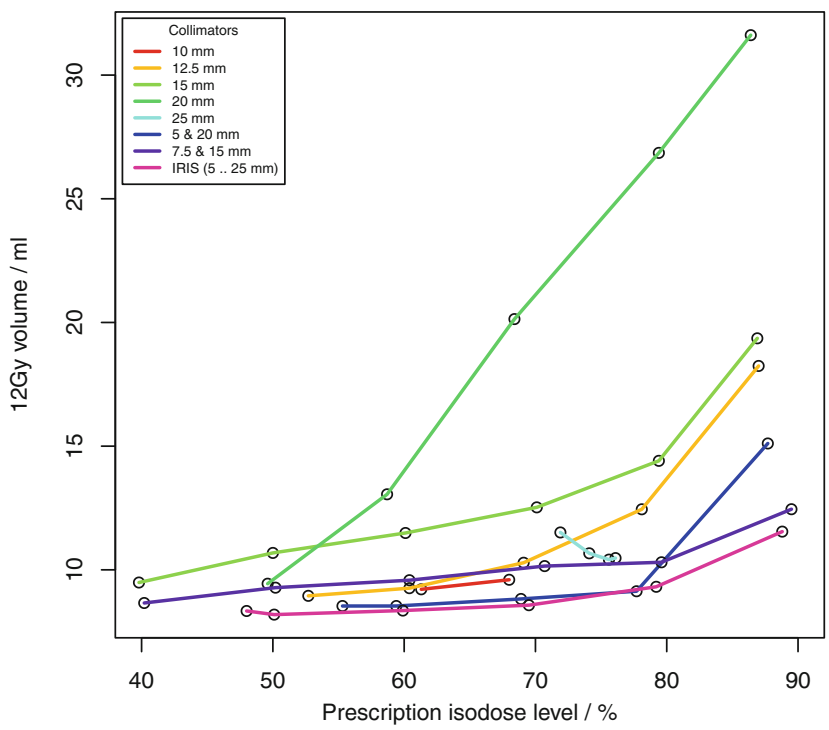

Fig. 2.2 e, $\mathbf{g}$ Conformity index (nCI) and $\mathbf{f}, \mathbf{h}$ volume of the $12 \mathrm{~Gy}$ isodose for 4 spherical phantom targets with volume $\mathbf{e}, \mathbf{f} 2.16 \mathrm{ml}$ and $\mathbf{g}, \mathbf{h} 7.77 \mathrm{ml}$ as a function of the achieved prescription isodose level

scatter plots of the resulting dose conformity index nCI and V12Gy as a function of the achieved PIL (box plots in supplementary material, Figures S 2 and S 3).

The achieved isodose levels were close to the intended target isodose levels, the deviation amounted to $0.1 \% \pm 2.6 \%$ (range: $-7.1 \%$ to $8.4 \%$ ) for Sequential optimization and $-0.5 \% \pm 5.5 \%$ (range: $-19.1 \%$ to $19.3 \%$ ) for $\mathrm{VOLO}^{\mathrm{TM}}$. Although for spherical targets only a limited range of PILs could be achieved with some collimator sets, the non-isocentric technique of the Cyberknife generally allowed the generation of plans with a PIL in the range of about $50-90 \%$. In contrast to isocentric planning, the achieved PIL was no longer dependent on collimator size; however, target size was a limiting factor in achieving low PILs. Inhomogeneous irradiation, i.e., low PILs could only be achieved if the size of one collimator in a used collimator set was smaller than the target size.

The quality of the plans and the treatment time varied greatly among the different collimator sets and prescription isodose levels. While conformity was generally high $(\mathrm{nCI} \leq 1.25)$ and showed very little dependence on the PIL in the phantom study using Sequential optimization, several outlier cases were observed for the clinical targets and the VOLO $^{\mathrm{TM}}$ optimizer associated with the collimator. Concerning the dose gradient of the plans, a much greater variability was observed, and there was a clear dependence of V12Gy on the PIL. In all targets and collimator sets, the lowest V12Gy was observed at isodose levels $\leq 65 \%$ and the highest V12Gy at isodose levels $\geq 80 \%$. But generally, the variability of $\mathrm{V} 12 \mathrm{~Gy}$ as a function of collimator selection 

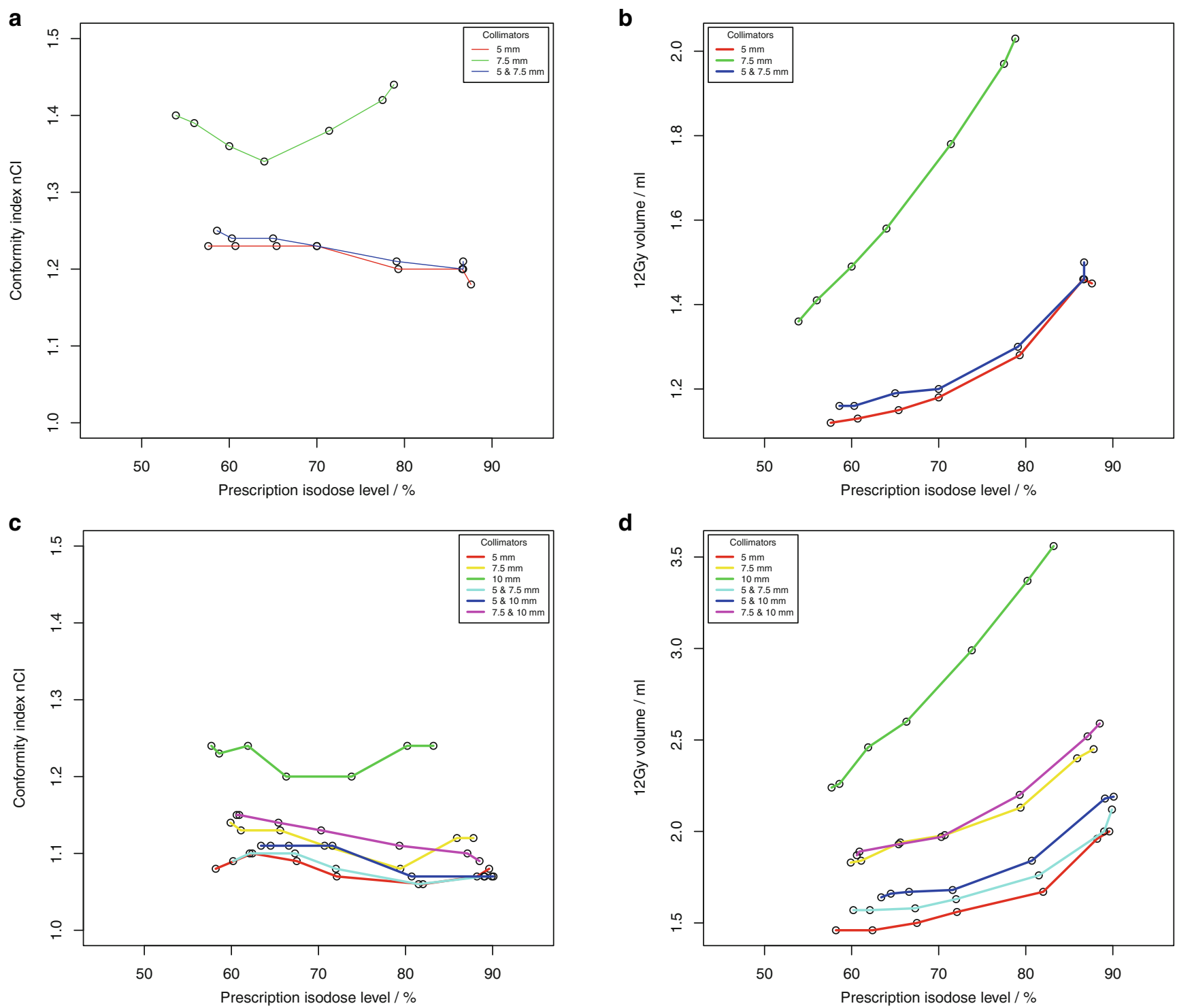

Fig. 3.1 a, c Conformity index $\mathrm{nCI}$ and $\mathbf{b}$, $\mathbf{d}$ volume of $12 \mathrm{~Gy}$ isodose for 4 clinical targets (single metastases) with volumes a, b $0.50 \mathrm{ml}$ and c, $\mathbf{d} 0.92 \mathrm{ml}$, as a function of the achieved prescription isodose level

was higher than the increase of V12Gy with the prescribed isodose, and except for the smallest target, there was always at least one collimator that showed a very pronounced dependence of V12Gy on isodose level. Field sizes of these collimators were all in the range of $70-80 \%$ of the target diameter. Excluding these outlier curves, for spherical targets, V12Gy was on average a factor of 1.7 to 2.2 larger at isodoses $>85 \%$ than at isodose levels $\leq 55 \%$, and for clinical targets, V12Gy was on average a factor of 1.1 to 1.3 larger at isodoses $>85 \%$ than at isodose levels $\leq 65 \%$. For the smallest target, V12Gy was increased only by a factor of 2.2 and not by 3.1 as in isocentric irradiation, demonstrating the superiority of non-isocentric beam superposition in producing homogeneous dose distributions. However, this superiority only applied to collimators whose field size was not in the range of 70-80\% of the target diameter, or to combinations of collimators. If the collimator was only slightly smaller than the target, the optimizer obviously needs to push the beams to the edge of the target and even beyond to avoid dose overlap in the center. Therefore, for these collimators, dose homogeneity could only be achieved by compromising the dose gradient.

A similar dependence of the dose gradient on the prescribed isodose level as found here was observed for all SRS platforms including robotic SRS [19-23]. Generally, $\mathrm{V} 12 \mathrm{~Gy}$ is lowest for prescriptions isodoses $\leq 65 \%$ and is increased by some $10 \%$ to $30 \%$ or more at $80 \%$ or $90 \%$. By ruling out operator dependence in our study, we were able to show that such dependence already arises for purely physical reasons and therefore cannot be avoided. However, 


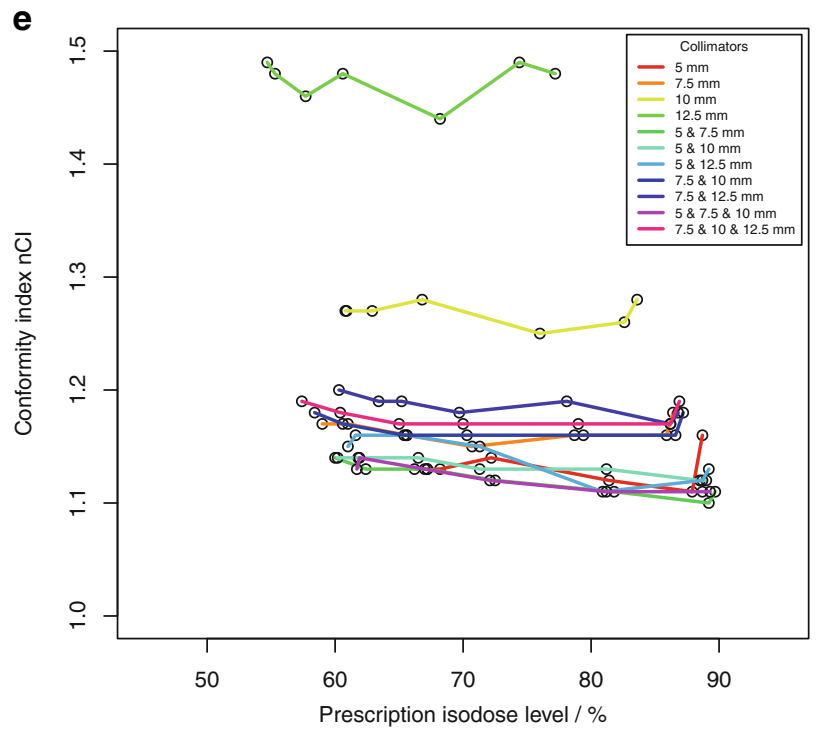

g

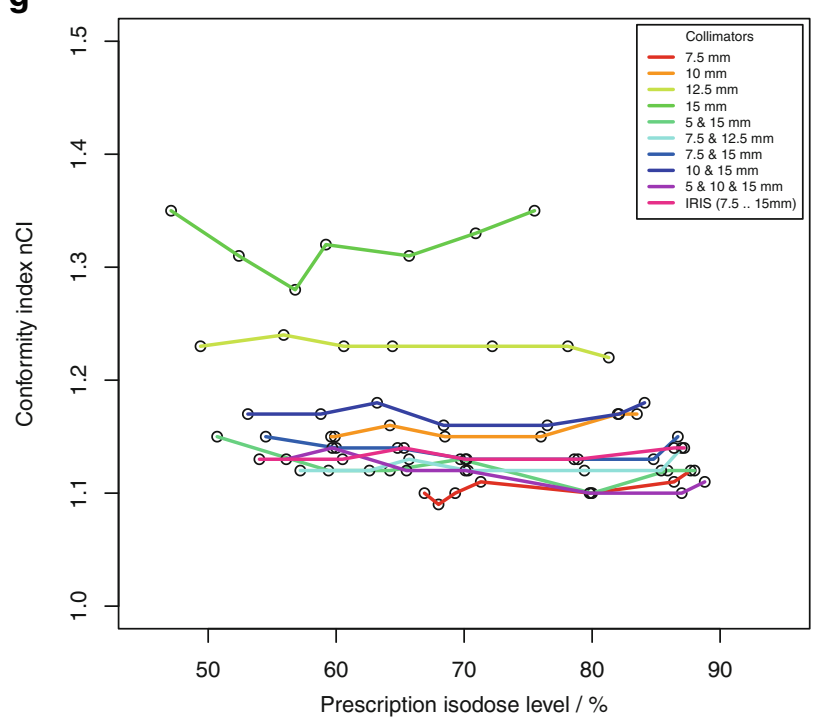

f

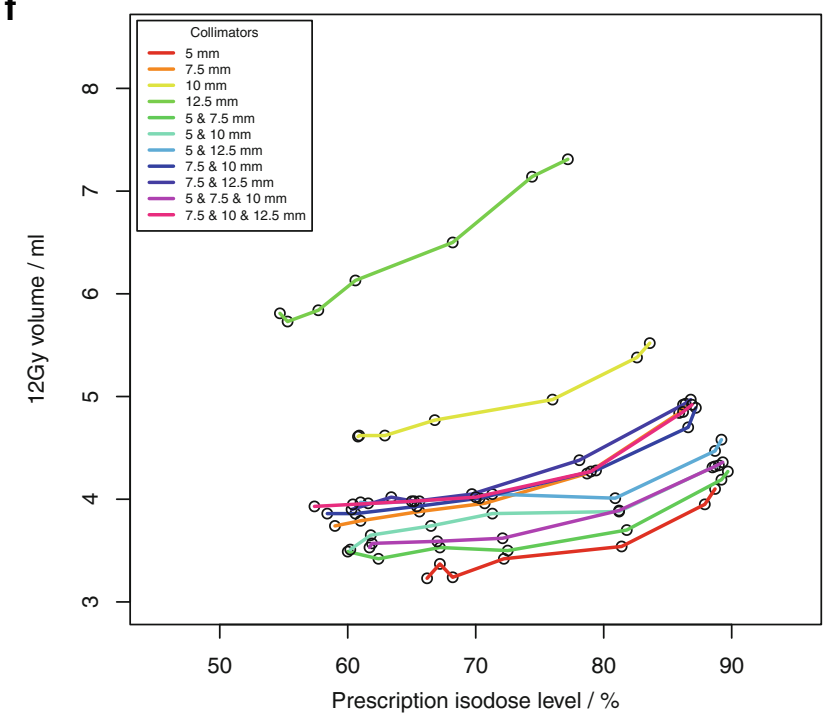

h

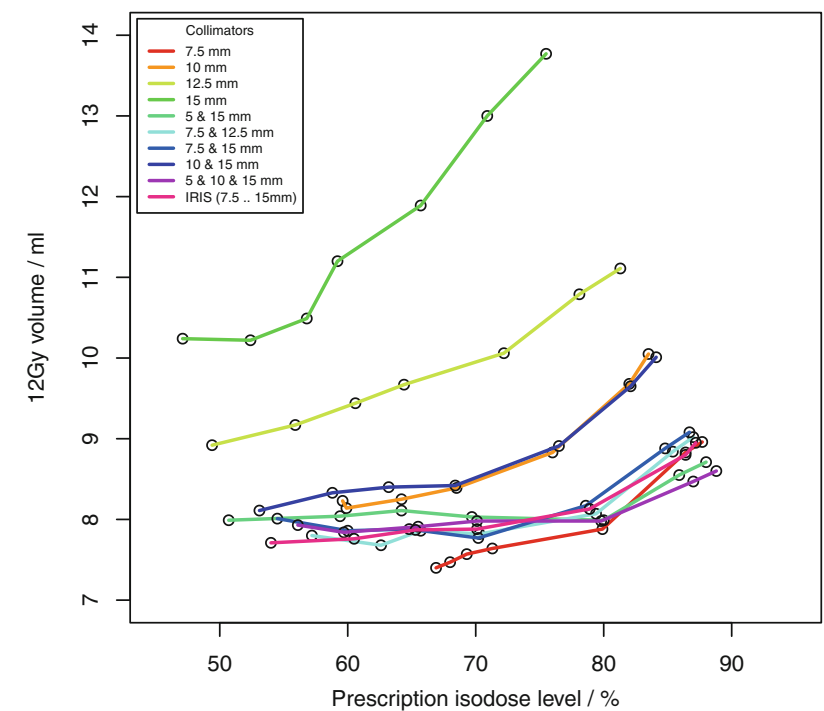

Fig. 3.2 e, $\mathbf{g}$ Conformity index $\mathrm{nCI}$ and $\mathbf{f}, \mathbf{h}$ volume of $12 \mathrm{~Gy}$ isodose for 4 clinical targets (single metastases) with volumes e, f $2.01 \mathrm{ml}$ and $\mathbf{g}, \mathbf{h} 5.68 \mathrm{ml}$ as a function of the achieved prescription isodose level

our results also show that the impact of collimator selection on plan quality is even larger than that of the PIL, emphasizing the need for experienced treatment planners.

Treatment time generally increased with increasing PIL, but again the main factor was collimator selection (supplementary material, Figures S4 and S5). There was a negative correlation of V12Gy with treatment time depending on collimator selection (Figs. 4 and 5). Within a collimator set, V12Gy increased with increasing PIL and thus with increasing treatment time (supplementary material, Figures S4 and S5), but when comparing different collimator settings, V12Gy decreased with increasing treatment time. The dependence of V12Gy on PIL and treatment time could be described by a linear model (Eq. 5), where $\mathrm{R}^{2}=0.96$ for clinical targets and $\mathrm{R}^{2}=0.82$ for phantom tar- gets. Results of the linear regression parameters showed an increase of V12Gy with increasing target volume and PIL and a negative correlation with treatment time (Table 1), where the treatment time can be used as an indicator for collimator selection. Plans with steep dose gradients (low V12Gy values) could be achieved with PILs up to $80 \%$, but the more homogeneous the selected PIL was, the greater the impact of collimator selection. Low V12Gy values with homogeneous PIL could only be achieved at large treatment times (Figs. 4 and 5).

Although there was no clear threshold, treatment plans with high conformity and low V12Gy tended to require a treatment time of $\geq 50 \mathrm{~min}$. Treatment plans that showed a pronounced dependence of V12Gy on the isodose level were considerably shorter ( $\leq 45 \mathrm{~min}$ ). In particular, planners 
a

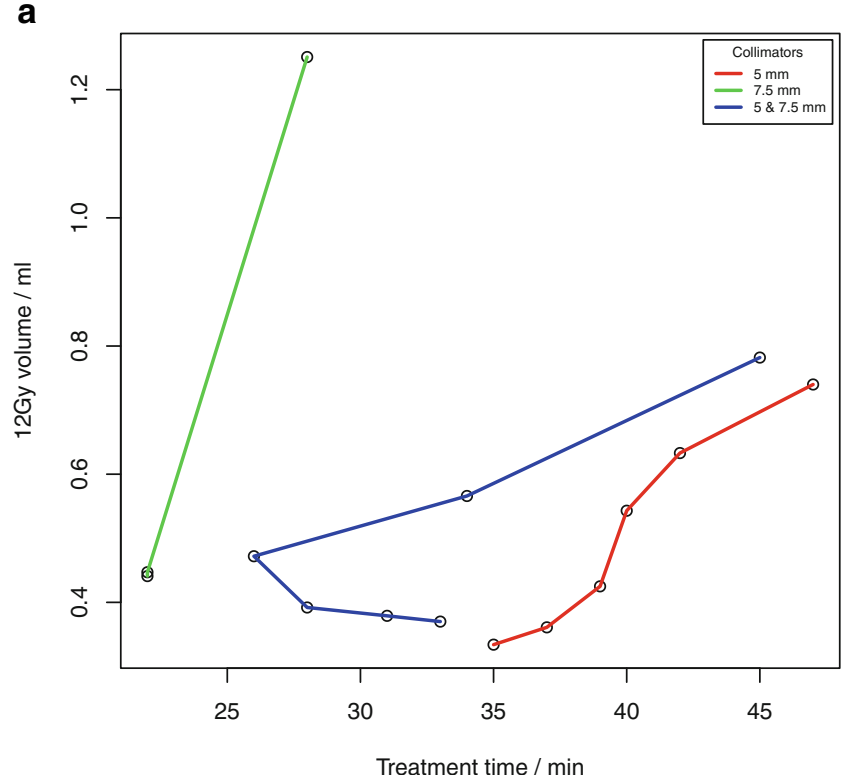

C

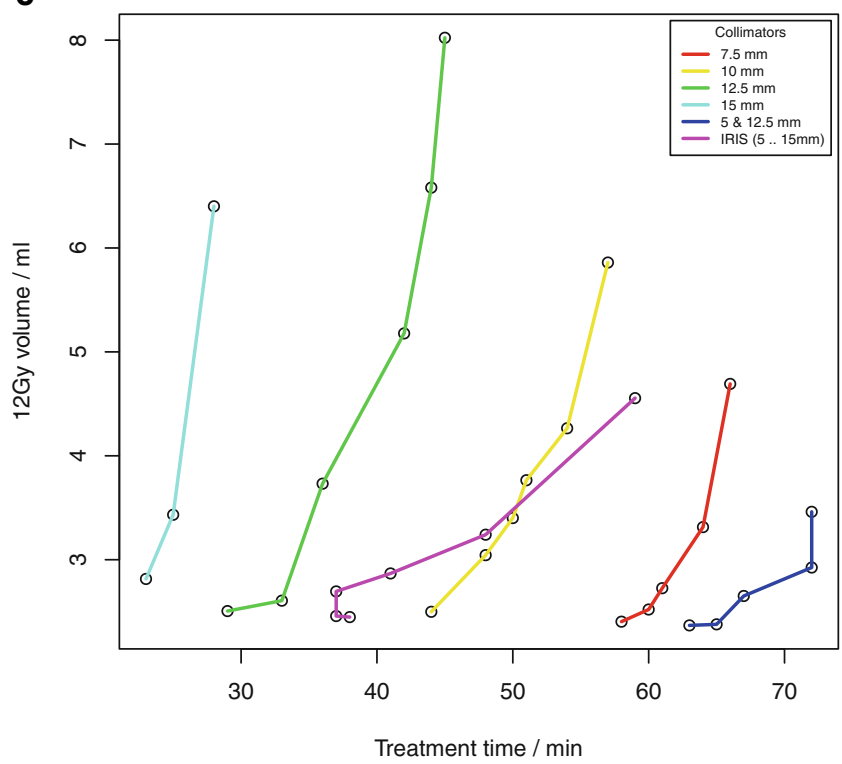

b

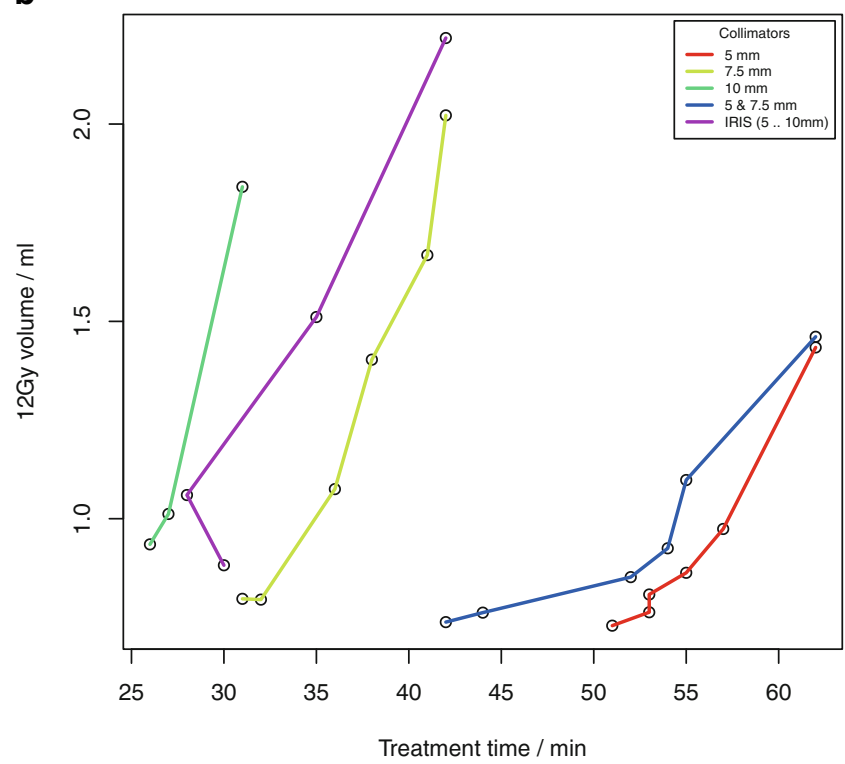

d

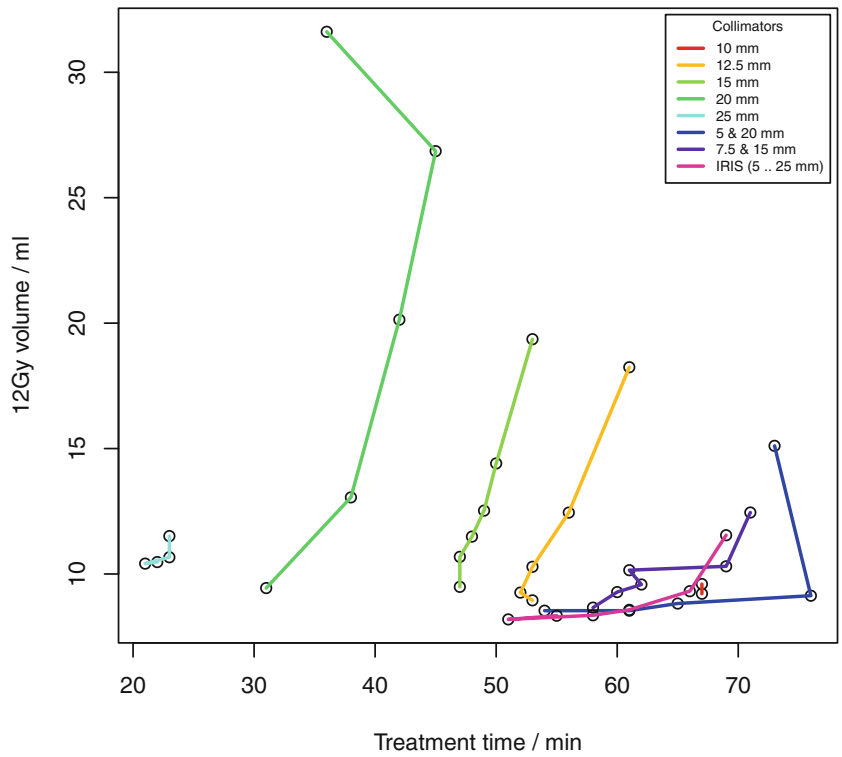

Fig. 4 Volume of the $12 \mathrm{~Gy}$ isodose for four spherical targets with volumes a $0.27 \mathrm{ml}, \mathbf{b} 0.55 \mathrm{ml}, \mathbf{c} 2.16 \mathrm{ml}$, and $\mathbf{d ~} 7.77 \mathrm{ml}$ as a function of the treatment time. Within one collimator set V12Gy increased with increasing prescribed isodose level (PIL)

should be aware that there is generally a strong trade-off between treatment time and dose gradient, as our results show. In our study, nCI, V12Gy, and treatment time were used to quantitatively characterize plan quality.

In general, in clinical situations, judgment about the quality and acceptability of a treatment plan will not be based solely on these three parameters. But V12Gy is highly correlated with other parameters as V10Gy $(\rho>0.99)$, V8Gy $(\rho>0.95)$, V4Gy $(\rho>0.53)$, GI $(\rho>0.81)$, and GM $(\rho>0.93)$ and thus may serve as a proxy for dose gradient and normal tissue toxicity, a view also supported by multiple SRS risk studies [32-37]. nCI is a measure of coverage and selectivity of the prescribed dose with respect to the target and was sufficient here as we only compared plans with identical coverage. Finally, treatment time was strongly correlated with two other metrics for plan quality, TotalMU $(\rho>0.94)$ and nBeams $(\rho>0.92)$. An increase in the TotalMU is associated with an increase in leakage radiation from the linac, although this should be balanced against the gain in improved dose gradient with increasing treatment duration. Short treatment time is mainly of practical advantage but has not been associated with improved clinical outcome [38]. 
a

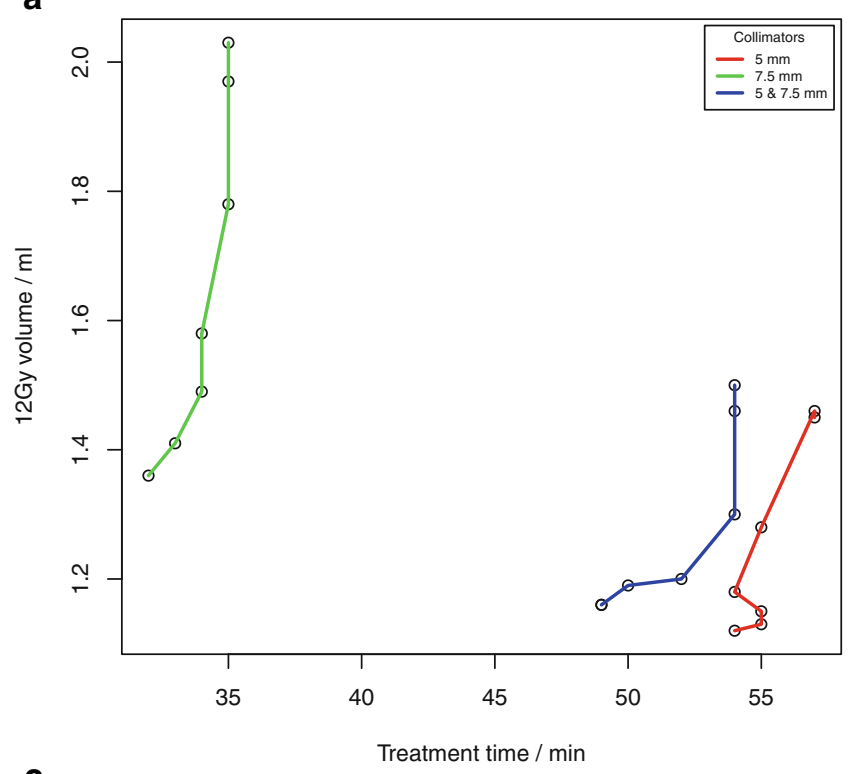

c

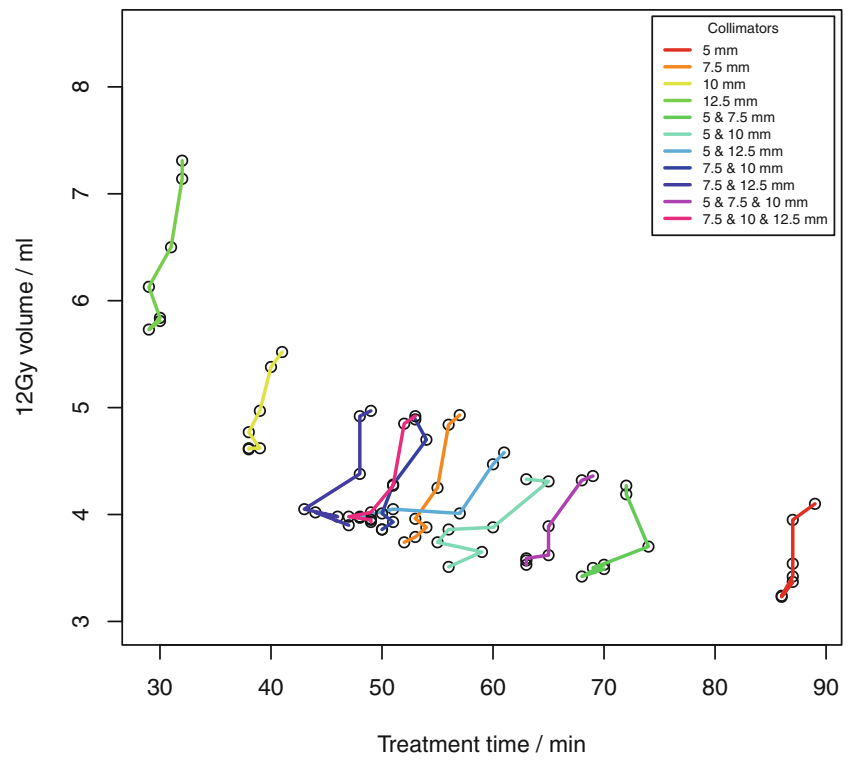

b

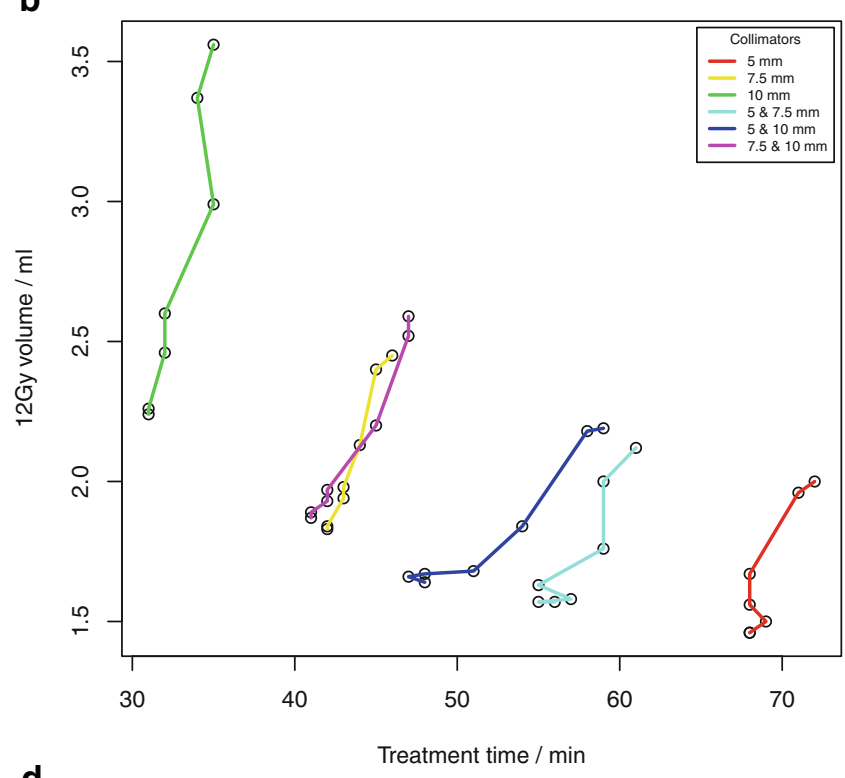

d

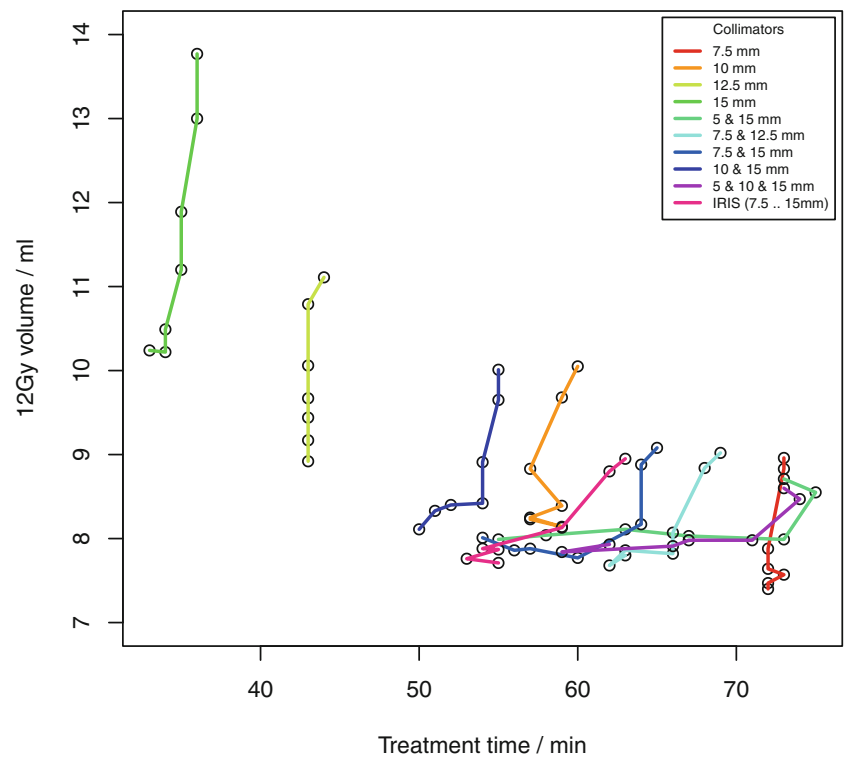

Fig. 5 Volume of the $12 \mathrm{~Gy}$ isodose for four single metastases with volume of a $0.50 \mathrm{ml}, \mathbf{b} 0.92 \mathrm{ml}, \mathbf{c} 2.01 \mathrm{ml}$ and $\mathbf{d} 5.68 \mathrm{ml}$ as a function of the treatment time. Within one collimator set V12Gy increased with increasing prescribed isodose level (PIL)

Table 1 Results of the regression coefficients $\beta_{i}$ for estimating the relationship between V12Gy and planning target volume (PTV), prescribed isodose level (PIL) and treatment time (TT) for all clinical targets as well as for all phantom targets (see Eq. 5)

\begin{tabular}{lll}
\hline & Clinical targets & Phantom targets \\
\hline$\beta_{0}$ & $9.23 \cdot 10^{-1}$ & $2.15 \cdot 10^{-1}$ \\
$\beta_{1}$ & $1.70 \cdot 10^{-3}$ & $1.34 \cdot 10^{-3}$ \\
$\beta_{2}$ & $1.45 \cdot 10^{-5}$ & $2.66 \cdot 10^{-5}$ \\
$\beta_{3}$ & $-2.13 \cdot 10^{-5}$ & $-1.30 \cdot 10^{-5}$ \\
\hline
\end{tabular}

\section{Limitations}

Our study was limited to 4 spherical and 4 clinical targets with a volume $\leq 7.77 \mathrm{ml}$. This is a representative sample of the spectrum of brain metastases treated in robotic SRS, but whether our results also apply to larger or more complicated shaped targets, e.g., meningioma or vestibular schwannoma is left open. Also it would be interesting to study cases with multiple targets or to extend our study to other SRS techniques. Lastly, we only studied conical collimators and the Iris collimator, as the InCise multileaf collimator (MLC) of the Cyberknife is mainly used for stereotactic body radiation therapy [39]. Finally, our study 
focused on basic physical and dosimetric aspects of dose prescription in robotic SRS. We did not examine planning skills and abilities, which are known to vary widely [15, 40-42], but we were able to identify parameters and pitfalls that affect plan quality. Further, we did not examine the impact of the dose prescription level in SRS on clinical outcomes. However, a recent study provides evidence that inhomogeneous dose distributions may more beneficial than traditional ICRU-compliant homogeneous dose prescription in the treatment of brain metastases [17].

In our study, we analyzed the influence of PIL and collimator selection on dose homogeneity and plan quality for isocentric as well as non-isocentric irradiation techniques, for phantom as well as clinical targets, and with two different optimization algorithms. We did not aim to compare both algorithms and discuss their benefits or pitfalls, as this topic has already been presented in the literature [28]. Our results show that for the dose plans of both algorithms, there is a similar dependency between dose conformity, V12Gy, and treatment time on PIL and collimator selection.

\section{Conclusions}

Using isocentric irradiation technique, selection of PILs is limited due to the size and shape of the beam profiles, whereas the achieved PIL is dependent on collimator sizes. In robotic SRS the non-isocentric irradiation technique allows the generation of highly conformal plans with steep dose gradients of inhomogeneous as well as homogeneous dose distributions with an intended PIL. Inhomogeneous dose distributions with a prescribed peripheral dose of $\leq 70 \%$ of the maximum dose showed the steepest dose gradients with simultaneous high dose escalation in the target and can be used to minimize toxicity to normal tissues. More homogeneous dose distributions within the target (up to $80 \%$ PIL) with a similarly steep dose gradient can be generated by using non-isocentric irradiation technique, careful selection of collimators and appropriate amount of treatment time. Generally, a combination of a mid-sized and a small collimator will be a good choice to achieve a desired PIL, steep dose gradient, and good conformity. PILs of $\geq 90 \%$ are associated with a marked and significant increase in off-target dose exposure, which must thoughtfully be traded off against the potential benefits of homogeneous on-target dose.

Supplementary Information The online version of this article (https:// doi.org/10.1007/s00066-021-01872-4) contains supplementary material, which is available to authorized users.

Funding No funds, grants, or other support was received.

Author Contribution HT conceived the study and supervised the project. All authors contributed to the study conception and design.
Material preparation and data collection were performed by ME and HT with support from $\mathrm{AH}$. $\mathrm{AH}$ and $\mathrm{ME}$ carried out the analysis and interpretation of data and wrote the manuscript. All authors provided critical feedback and helped shape the research, analysis and manuscript. All authors read and approved the final manuscript.

Funding Open Access funding enabled and organized by Projekt DEAL.

\section{Declarations}

Conflict of interest A. Hellerbach, M. Eichner, D. Rueß, K. Luyken, M. Hoevels, M. Judge, C. Baues, M. Ruge, M. Kocher and H. Treuer declare that they have no competing interests.

Ethical standards This retrospective study was approved by the local ethics committee of the University Hospital of Cologne (file number 16-476). Consent to participate: Not applicable. Consent for publication: Not applicable

Open Access This article is licensed under a Creative Commons Attribution 4.0 International License, which permits use, sharing, adaptation, distribution and reproduction in any medium or format, as long as you give appropriate credit to the original author(s) and the source, provide a link to the Creative Commons licence, and indicate if changes were made. The images or other third party material in this article are included in the article's Creative Commons licence, unless indicated otherwise in a credit line to the material. If material is not included in the article's Creative Commons licence and your intended use is not permitted by statutory regulation or exceeds the permitted use, you will need to obtain permission directly from the copyright holder. To view a copy of this licence, visit http://creativecommons.org/licenses/by/4. $0 \%$

\section{References}

1. Kocher M, Soffietti R, Abacioglu U, Villà S, Fauchon F, Baumert BG et al (2011) Adjuvant whole-brain radiotherapy versus observation after radiosurgery or surgical resection of one to three cerebral metastases: results of the EORTC 22952-26001 study. J Clin Oncol 29(2):134-141. https://doi.org/10.1200/JCO.2010.30.1655

2. Kocher M, Wittig A, Piroth MD, Treuer H, Seegenschmiedt H, Ruge M et al (2014) Stereotactic radiosurgery for treatment of brain metastases. A report of the DEGRO Working Group on Stereotactic Radiotherapy. Strahlenther Onkol 190(6):521-532. https://doi.org/ 10.1007/s00066-014-0648-7

3. Monaco EA III, Parry PV, Grandhi R, Niranjan A, Kano H, Lunsford LD (2012) Future perspectives on brain metastasis management. Prog Neurol Surg 25:287-308. https://doi.org/10.1159/ 000331201

4. Romanelli P, Conti A, Redaelli I, Martinotti AS, Bergantin A, Bianchi LC et al (2019) Cyberknife radiosurgery for trigeminal neuralgia. Cureus 11(10):e6014. https://doi.org/10.7759/cureus. 6014

5. Romanelli P, Conti A, Pontoriero A, Ricciardi GK, Tomasello F, De Renzis C, Innocenzi G, Esposito V, Cantore G (2009) Role of stereotactic radiosurgery and fractionated stereotactic radiotherapy for the treatment of recurrent glioblastoma multiforme. Neurosurg Focus 27(6):E8. https://doi.org/10.3171/2009.9.FOCUS09187

6. Rueß D, Pöhlmann L, Hellerbach A, Hamisch C, Hoevels M, Treuer $\mathrm{H}$ et al (2018) Acoustic neuroma treated with stereotactic radiosurgery: follow-up of 335 patients. World Neurosurg 116:e194-e202. https://doi.org/10.1016/j.wneu.2018.04.149 
7. Stangerup SE, Tos M, Thomsen J, Caye-Thomasen P (2010) True incidence of vestibular schwannoma? Neurosurgery 67(5):13351340. https://doi.org/10.1227/NEU.0b013e3181f22660 (discussion 1340)

8. Kroeze SG, Fritz C, Hoyer M, Lo SS, Ricardi U, Sahgal A, Stahel R, Stupp R, Guckenberger M (2017) Toxicity of concurrent stereotactic radiotherapy and targeted therapy or immunotherapy: a systematic review. Cancer Treat Rev 53:25-37. https://doi.org/10. 1016/j.ctrv.2016.11.013

9. Benedict SH, Yenice KM, Followill D, Galvin JM, Hinson W, Kavanagh B et al (2010) Stereotactic body radiation therapy: the report of AAPM Task Group 101. Med Phys 37(8):4078-4101. https://doi. org/10.1118/1.3438081

10. Guckenberger M, Baus WW, Blanck O, Combs SE, Debus J, Engenhart-Cabillic R et al (2020) Definition and quality requirements for stereotactic radiotherapy: consensus statement from the DEGRO/DGMP Working Group Stereotactic Radiotherapy and Radiosurgery. Strahlenther Onkol 196(5):417-420. https://doi.org/ 10.1007/s00066-020-01603-1

11. Schmitt D, Blanck O, Gauer T, Fix MK, Brunner TB, Fleckenstein J et al (2020) Technological quality requirements for stereotactic radiotherapy: expert review group consensus from the DGMP Working Group for Physics and Technology in Stereotactic Radiotherapy. Strahlenther Onkol 196(5):421-443. https://doi.org/10.1007/ s00066-020-01583-2

12. Seuntjens J, Lartigau EF, Cora S, Ding GX, Goetsch S, Nuyttens J et al (2014) ICRU report 91. Prescribing, recording, and reporting of stereotactic treatments with small photon beams. J ICRU 14(2): $1-160$

13. Schweikard A, Schlaefer A, Adler JR Jr (2006) Resampling: an optimization method for inverse planning in robotic radiosurgery. Med Phys 33(11):4005-4011. https://doi.org/10.1118/1.2357020

14. Dimitriadis A, Kirkby KJ, Nisbet A, Clark CH (2016) Current status of cranial stereotactic radiosurgery in the UK. Br J Radiol 89(1058):20150452. https://doi.org/10.1259/bjr.20150452

15. Eaton DJ, Lee J, Patel R, Millin AE, Paddick I, Walker C (2018) Stereotactic radiosurgery for benign brain tumors: results of multicenter benchmark planning studies. Pract Radiat Oncol 8(5):e295-e304. https://doi.org/10.1016/j.prro.2018.02.006

16. Gevaert T, Levivier M, Lacornerie T, Verellen D, Engels B, Reynaert $\mathrm{N}$ et al (2013) Dosimetric comparison of different treatment modalities for stereotactic radiosurgery of arteriovenous malformations and acoustic neuromas. Radiother Oncol 106(2):192-197. https://doi.org/10.1016/j.radonc.2012.07.002

17. Lucia F, Key S, Dissaux G, Goasduff G, Lucia AS, Ollivier L et al (2019) Inhomogeneous tumor dose distribution provides better local control than homogeneous distribution in stereotactic radiotherapy for brain metastases. Radiother Oncol 130:132-138. https://doi. org/10.1016/j.radonc.2018.06.039

18. Romano KD, Trifiletti DM, Garda A, Xu Z, Schlesinger D, Watkins WT et al (2017) Choosing a prescription Isodose in stereotactic radiosurgery for brain metastases: implications for local control. World Neurosurg 98:761-767.e1. https://doi.org/10. 1016/j.wneu.2016.11.038

19. Chan M, Wong M, Leung R, Cheung S, Blanck O (2018) Optimizing the prescription isodose level in stereotactic volumetric-modulated arc radiotherapy of lung lesions as a potential for dose deescalation. Radiat Oncol 13(1):24. https://doi.org/10.1186/s13014018-0965-6

20. Ding C, Solberg TD, Hrycushko B, Xing L, Heinzerling J, Timmerman RD (2013) Optimization of normalized prescription isodose selection for stereotactic body radiation therapy: conventional vs robotic linac. Med Phys 40(5):51705. https://doi.org/10.1118/1. 4798944

21. Ohtakara K, Hayashi S, Tanaka H, Hoshi H (2012) Consideration of optimal isodose surface selection for target coverage in micro- multileaf collimator-based stereotactic radiotherapy for large cystic brain metastases: comparison of $90 \%, 80 \%$ and $70 \%$ isodose surface-based planning. Br J Radiol 85(1017):e640-e646. https://doi. org/10.1259/bjr/21015703

22. Xu Q, Fan J, Grimm J, LaCouture T, Asbell S, Park JH et al (2017) The dosimetric impact of the prescription isodose line (IDL) on the quality of robotic stereotactic radiosurgery (SRS) plans. Med Phys 44(12):6159-6165. https://doi.org/10.1002/mp.12630

23. Zhao B, Jin JY, Wen N, Huang Y, Siddiqui MS, Chetty IJ et al (2014) Prescription to 50-75\% isodose line may be optimum for linear accelerator based radiosurgery of cranial lesions. J Radiosurg SBRT 3(2):139-147

24. Hellerbach A, Luyken K, Hoevels M, Gierich A, Rueß D, Baus WW et al (2017) Radiotoxicity in robotic radiosurgery: proposing a new quality index for optimizing the treatment planning of brain metastases. Radiat Oncol 12(1):136. https://doi.org/10.1186/s13014017-0867-z

25. Treuer U, Treuer H, Hoevels M, Müller RP, Sturm V (1998) Computerized optimization of multiple isocentres in stereotactic convergent beam irradiation. Phys Med Biol 43(1):49-64. https://doi.org/ 10.1088/0031-9155/43/1/004

26. Schlaefer A, Schweikard A (2008) Stepwise multi-criteria optimization for robotic radiosurgery. Med Phys 35(5):2094-2103. https://doi.org/10.1118/1.2900716

27. Echner GG, Kilby W, Lee M, Earnst E, Sayeh S, Schlaefer A et al (2009) The design, physical properties and clinical utility of an iris collimator for robotic radiosurgery. Phys Med Biol 54(18):5359-5380. https://doi.org/10.1088/0031-9155/54/18/001

28. Zeverino M, Marguet M, Zulliger C, Durham A, Jumeau R, Herrera $\mathrm{F}$ et al (2019) Novel inverse planning optimization algorithm for robotic radiosurgery: first clinical implementation and dosimetric evaluation. Phys Med 64:230-237. https://doi.org/10.1016/ j.ejmp.2019.07.020

29. van't Riet A, Mak AC, Moerland MA, Elders LH, van der Zee W (1997) A conformation number to quantify the degree of conformality in brachytherapy and external beam irradiation: application to the prostate. Int J Radiat Oncol Biol Phys 37(3):731-736. https:// doi.org/10.1016/s0360-3016(96)00601-3

30. Paddick I, Lippitz B (2006) A simple dose gradient measurement tool to complement the conformity index. J Neurosurg 105(Suppl):194-201. https://doi.org/10.3171/sup.2006.105.7.194

31. Shiraishi S, Tan J, Olsen LA, Moore KL (2015) Knowledge-based prediction of plan quality metrics in intracranial stereotactic radiosurgery. Med Phys 42(2):908. https://doi.org/10.1118/1.4906183

32. Blonigen BJ, Steinmetz RD, Levin L, Lamba MA, Warnick RE, Breneman JC (2010) Irradiated volume as a predictor of brain radionecrosis after linear accelerator stereotactic radiosurgery. Int $\mathrm{J}$ Radiat Oncol Biol Phys 77(4):996-1001. https://doi.org/10.1016/j. ijrobp.2009.06.006

33. Flickinger JC, Kondziolka D, Pollock BE, Maitz AH, Lunsford LD (1997) Complications from arteriovenous malformation radiosurgery: multivariate analysis and risk modeling. Int $\mathrm{J}$ Radiat Oncol Biol Phys 38(3):485-490. https://doi.org/10.1016/s03603016(97)89481-3

34. Korytko T, Radivoyevitch T, Colussi V, Wessels BW, Pillai K, Maciunas RJ et al (2006) 12 Gy gamma knife radiosurgical volume is a predictor for radiation necrosis in non-AVM intracranial tumors. Int J Radiat Oncol Biol Phys 64(2):419-424. https://doi.org/ 10.1016/j.ijrobp.2005.07.980

35. Lawrence YR, Li XA, el Naqa I, Hahn CA, Marks LB, Merchant TE et al (2010) Radiation dose-volume effects in the brain. Int J Radiat Oncol Biol Phys 76(3 Suppl):S20-S27. https://doi.org/ 10.1016/j.ijrobp.2009.02.091

36. Minniti G, Clarke E, Lanzetta G, Osti MF, Trasimeni G, Bozzao A et al (2011) Stereotactic radiosurgery for brain metastases: analy- 
sis of outcome and risk of brain radionecrosis. Radiat Oncol 6:48. https://doi.org/10.1186/1748-717X-6-48

37. Voges J, Treuer H, Sturm V, Büchner C, Lehrke R, Kocher M et al (1996) Risk analysis of linear accelerator radiosurgery. Int J Radiat Oncol Biol Phys 36(5):1055-1063. https://doi.org/10.1016/s03603016(96)00422-1

38. Wilhelm ML, Chan MKH, Abel B, Cremers F, Siebert FA, Wurster S et al (2020) Tumor-dose-rate variations during robotic radiosurgery of oligo and multiple brain metastases. Strahlenther Onkol. https://doi.org/10.1007/s00066-020-01652-6

39. Kathriarachchi V, Shang C, Evans G, Leventouri T, Kalantzis G (2016) Dosimetric and radiobiological comparison of CyberKnife $\mathrm{M}^{\mathrm{TM}}$ InCise multileaf collimator over IRIS ${ }^{\mathrm{TM}}$ variable collimator in prostate stereotactic body radiation therapy. J Med Phys 41(2):135-143. https://doi.org/10.4103/0971-6203.181638
40. Blanck O, Wang L, Baus W, Grimm J, Lacornerie T, Nilsson J et al (2016) Inverse treatment planning for spinal robotic radiosurgery: an international multi-institutional benchmark trial. J Appl Clin Med Phys 17(3):313-330. https://doi.org/10.1120/jacmp.v17i3. 6151

41. Esposito M, Masi L, Zani M, Doro R, Fedele D, Garibaldi C et al (2019) SBRT planning for spinal metastasis: indications from a large multicentric study. Strahlenther Onkol 195(3):226-235. https://doi.org/10.1007/s00066-018-1383-2

42. Schoonbeek A, Monshouwer R, Hanssens P, Raaijmakers E, Nowak P, Marijnissen JP et al (2010) Intracranial radiosurgery in the Netherlands. A planning comparison of available systems with regard to physical aspects and workload. Technol Cancer Res Treat 9(3):279-290. https://doi.org/10.1177/153303461000900307 